\title{
Atrial Fibrillation Prediction by Surgical Risk Scores Following Isolated Coronary Artery Bypass Grafting Surgery
}

\author{
Ali Dogan1, Fusun Gunesdogdu2, Kenan Sever33, Serkan Kahraman4, Denyan Mansuroglu33, Mustafa Yolcu1, \\ Emrah Ozdemir ${ }^{1}$ and Nuri Kurtoglu ${ }^{1}$ \\ Department of Cardiology1 / Family Medicine² / Cardiovascular Surgery³, Faculty of Medicine, Istanbul Yeni Yuzyil University, \\ Gaziosmanpasa Hospital, Gaziosmanpasa, Istanbul, Turkey \\ Department of Cardiology4, Istanbul Mehmet Akif Ersoy Thoracic and Cardiovascular Surgery Center, Training and Research Hospital, \\ Istanbul, Turkey
}

\begin{abstract}
Objective: To compare surgical risk scores including Euroscore II, STS and Logistic Euroscore for their predictive ability about postoperative atrial fibrillation (POAF).

Study Design: Prospective cohort study.

Place and Duration of Study: Istanbul Yeni Yuzyil University, Gaziosmanpasa Hospital and Istanbul Mehmet Akif Ersoy Thoracic and Cardiovascular Surgery Center, from June to December 2018.

Methodology: One hundred and four patients, undergoing isolated coronary artery bypass grafting operation, were enrolled. Surgical risk scores, clinical, laboratory and echocardiographic parameters were compared between POAF-positive and POAF-negative groups

Results: Of the 104 patients included, $23(22.1 \%)$ patients developed atrial fibrillation postoperatively. Peripheral artery disease, carotid artery disease, current smoking, cardiopulmonary bypass time, left atrial diameter, and Syntax II score were found to be associated with POAF. Among these, peripheral artery disease and cardiopulmonary bypass time were independently related with POAF. Euroscore II $(p=0.005)$, STS $(p=0.026)$ and Logistic Euroscore $(p=0.032)$ were all statistically higher in POAF developing patients. In terms of ROC analysis, area under the curve was higher in Euroscore II (0.697) than STS and Logistic Euroscore (0.658 and 0.652, respectively).

Conclusion: Euroscore II, STS and Logistic Euroscore were all associated with POAF development. However, Euroscore II could be a better option for the prediction of POAF.
\end{abstract}

Key Words: Coronary artery bypass grafting surgery, Atrial fibrillation, Euroscore II, STS score, Logistic Euroscore.

How to cite this article: Dogan A, Gunesdogdu F, Sever K, Kahraman S, Mansuroglu D, Yolcu M, Ozdemir E, Kurtoglu N. Atrial fibrillation prediction by surgical risk scores following isolated coronary artery bypass grafting surgery. J Coll Physicians Surg Pak 2019; 29(11):1038-42.

\section{INTRODUCTION}

Atrial fibrillation (AF) still stays one of the major reasons of ischemic stroke, heart failure, and sudden cardiac death. ${ }^{1}$ Postoperative atrial fibrillation (POAF) is very common arrhythmia after coronary artery bypass grafting surgery $(C A B G)$ resulting in increased mortality and morbidity rates.2,3 Its incidence is estimated to be occurring in $15-45 \%$ of patients in spite of progression in postoperative management. ${ }^{1}$ Various surgical risk models can be used to predict postoperative mortality. The European System for Cardiac Operative Risk Evaluation (Euroscore-I) and The Society of Thoracic Surgeons (STS) score are still used to estimate preoperative risk before surgery. Euroscore-II was

Correspondence to: Dr. Ali Dogan, Department of Cardiology,

Faculty of Medicine, Istanbul Yeni Yuzyil University,

Gaziosmanpasa Hospital, Gaziosmanpasa, Istanbul, Turkey

E-mail:drdali@hotmail.com

Received: March 12, 2019; Revised: August 19, 2019;

Accepted: August 19, 2019 developed as an updated version in 2012.4 The Logistic Euroscore is based on an international European database consisting of patients mainly with CABG. 5 Application of these scoring systems for the prediction of POAF has not been clearly assessed.

The aim of this study was to evaluate the predictive value of Euroscore II, Logistic Euroscore and STS scoring systems for identifying POAF.

\section{METHODOLOGY}

It was a multi-center, observational, prospective study conducted at Istanbul Yeni Yuzyil University, Gaziosmanpasa Hospital and Istanbul Mehmet Akif Ersoy Thoracic and Cardiovascular Surgery Center. One hundred and four patients undergoing isolated on-pump CABG were consecutively included from June to December 2018. Exclusion criteria were off-pump coronary bypass surgery, a history of permanent or paroxysmal AF, current usage of sotalol and amiodarone, valvular heart disease necessitating surgery and ischemic mitral regurgitation, left atrial diameter over $50 \mathrm{~mm}$, malignant disease, 
active infection, advanced liver failure, hyperthyroidism. The study was approved by the local institutional Ethical Committee of Istanbul Yeni Yuzyil University; written informed consent was acquired from patients.

Logistic Euroscore and Euroscore-II and the STS score calculations for isolated CABG were implemented with the online calculator. The Euroscore-II and Logistic Euroscore consist of 18 and 17 variables, respectively. The STS score comprises 41 variables from 8 different categories.

Extent and severity of coronary artery disease was determined angiographically by the online Syntax score calculator. Syntax II was also calculated online by uniting Syntax score with clinical variables. These calculations were made by independent physician unaware of the study objective. Clinical features of the patients, echocardiographic parameters and biochemical tests were noted before the operation.

Thiopental sodium $(10 \mu \mathrm{g} / \mathrm{kg})$, midazolam $(0.1 \mathrm{mg} / \mathrm{kg})$, sufentanil $(1.5 \mu \mathrm{g} / \mathrm{kg})$ and rocuronium $0.5(\mu \mathrm{g} / \mathrm{kg})$ were used for the induction of general anesthesia. The operations were carried out by standard midline sternotomy. Intravenous heparin was applied with a dose of $100 \mathrm{lU} / \mathrm{kg}$ to achieve activated clotting time (ACT) over 400 seconds. Myocardial protection was maintained with antegrade isothermic blood cardioplegia with high potassium level. Cardiopulmonary bypass and cross-clamp times were noted. The effect of heparin was neutralised by protamine sulfate.

After CABG, all the patients were monitored in the surgical intensive care unit and a 12-lead ECG was taken from the patients every 12 or 24 hours during hospital stay. When the patients complained of palpitation, angina, dyspnea, an additional 12-lead ECG was obtained. POAF was defined as an episode lasting than 60 seconds. ${ }^{6}$ Amiodarone perfusion was used to restore the sinus rhythm

Statistical analyses were performed using SPSS software (version 22.0; SPSS Inc., Chicago, IL, USA). Continuous variables were reported as mean \pm standard deviation (SD) or median (min-max). Frequencies and percentages were used for categorical data. KolmogorovSmirnov test was used to identify normality of distribution. Student's t-test and Mann-Whitney U-test were used to compare continuous variables. Pearson Chisquare test or Fisher's exact test were performed to compare categorical data.

Significant variables in the univariate analysis were incorporated into multivariate logistic regression with backward selection.

For each surgical risk scoring system, receiver operating characteristic (ROC) curves were used to define the sensitivity, specificity and the area under the resulting curve (AUC). AUC values were compared to determine the predictive ability of all scoring systems. A p-value less than 0.05 was considered statistically significant.

\section{RESULTS}

One hundred and four consecutive isolated CABG patients were included and evaluated. Twenty-three (22.1\%) patients developed atrial fibrillation post-operatively. Comparison of POAF negative and positive groups in terms of clinical, echocardiographic and laboratory parameters were presented in Table I. Patients with POAF had higher percentages of peripheral artery

Table I: Comparison of POAF negative and positive groups according to clinical, laboratory and echocardiographic parameters.

\begin{tabular}{|c|c|c|c|}
\hline & $\begin{array}{c}\text { POAF - } \\
\mathrm{n}: 83\end{array}$ & $\begin{array}{c}\text { POAF+ } \\
\mathrm{n}: 21 \\
\end{array}$ & $P$ \\
\hline Age (years) & $60 \pm 9$ & $63 \pm 9$ & 0.178 \\
\hline Gender (male), n, \% & $63(75.9)$ & $15(71.4)$ & 0.672 \\
\hline Hypertension, n, \% & $56(67.5)$ & $17(81.0)$ & 0.228 \\
\hline Diabetes mellitus, $n, \%$ & $37(44.6)$ & $9(42.9)$ & 0.887 \\
\hline Hyperlipidemia, n, \% & $36(43.4)$ & $9(42.9)$ & 0.966 \\
\hline Current smoking, n, \% & $21(25.3)$ & $12(57.1)$ & 0.005 \\
\hline Previous MI, n, \% & $10(12.0)$ & $5(23.8)$ & 0.153 \\
\hline Chronic renal failure, n, \% & $3(3.6)$ & $0(0)$ & 0.505 \\
\hline History of stroke, n, \% & $2(2,4)$ & $0(0)$ & 0.635 \\
\hline Peripheral artery disease, $n, \%$ & $1(1.2)$ & $7(33.3)$ & 0.001 \\
\hline Carotid artery disease, $\mathrm{n}, \%$ & $7(8.4)$ & $6(28.6)$ & 0.023 \\
\hline Stable angina pectoris, n, \% & $65(78.3)$ & $19(90.5)$ & 0.171 \\
\hline NSTEMI, n, \% & $15(18.1)$ & $2(9.5)$ & 0.280 \\
\hline STEMI, n, \% & $2(2.4)$ & $0(0)$ & 0.635 \\
\hline Cross-clamp time & $50 \pm 15$ & $56 \pm 16$ & 0.104 \\
\hline Cardiopulmonary bypass time & $83 \pm 25$ & $96 \pm 31$ & 0.048 \\
\hline WBC, $\mu \mathrm{l}$ & $7830(4100-17160)$ & $8170(4500-15000)$ & 0.811 \\
\hline Hemoglobin g/dL & $14.2(8.6-17)$ & $13.6(10.6-18.7)$ & 0.209 \\
\hline Platelet, $103 / \mu \mathrm{l}$ & $256385 \pm 66298$ & $260285 \pm 67894$ & 0.811 \\
\hline Mean platelet volume, fL & $10.6 \pm 1.0$ & $10.6 \pm 0.7$ & 0.745 \\
\hline RCDW, \% & $13(11.4-16.9)$ & $13.1(11.2-15.1)$ & 0.615 \\
\hline CRP, mg/dL & $4.9(0.42-207.9)$ & $5.7(1.41-18.70)$ & 0.252 \\
\hline Urea, mg/dL & $15.1(6.5-58.9)$ & $17.0(11.7-30.5)$ & 0.052 \\
\hline Creatinine $\mathrm{mg} / \mathrm{dL}$ & $0.9(0.47-10.66)$ & $0.87(0.67-1.72)$ & 0.283 \\
\hline LDL-C, mg/dL & $122 \pm 44.7$ & $123 \pm 34.1$ & 0.904 \\
\hline $\mathrm{HDL}-\mathrm{C}, \mathrm{mg} / \mathrm{dL}$ & $42,7 \pm 9.8$ & $46.2 \pm 11.6$ & 0.158 \\
\hline Triglyceride, $\mathrm{mg} / \mathrm{dL}$ & $165(53-724)$ & $170(86-680)$ & 0.686 \\
\hline LV-EF, \% & $58(35-68)$ & $58(35-66)$ & 0.860 \\
\hline LV-ESD, cm & $3.3(2.2-4.7)$ & $3.2(2.9-4.9)$ & 0.474 \\
\hline LV-EDD, cm & $4.7 \pm 0.4$ & $4.9 \pm 0.5$ & 0.118 \\
\hline Left atrium diameter, $\mathrm{cm}$ & $3.7(2.9-4.6)$ & $4.0(3.3-4.6)$ & 0.014 \\
\hline
\end{tabular}

MI: Myocardial infarction, NSTEMI: Non-ST segment elevation myocardial infarction, STEMI: ST segment elevation myocardial infarction, WBC: White blood cells, RCDW: Red cell distribution width, CRP:C-reactive protein, LDL-C: Low density lipoprotein-cholesterol, HDL-C: High density lipoprotein- cholesterol, LV-EF: Left ventricle-ejection fraction, LV-ESD: Left ventricle-end systolic diameter, LV-EDD: Left ventricle-end diastolic diameter.

Table II: Comparison of Syntax, Syntax II, Euroscore II, STS and Logistic Euroscore in POAF + and - groups.

\begin{tabular}{l|c|c|c}
\hline & POAF - & POAF+ & P \\
\hline Syntax & $19.0(10.0-40.5)$ & $20.5(10.0-30.0)$ & 0.207 \\
\hline Syntax II & $23.5(5.7-42.0)$ & $25.6(13.8-50.9)$ & 0.023 \\
\hline Euroscore II & $1.52(0.55-5.71)$ & $2.45(0.83-12.69)$ & 0.005 \\
\hline STS & $0.634(0.202-3.240)$ & $1.240(0.236-3.210)$ & 0.026 \\
\hline Logistic Euroscore & $2.10(0.88-8.62)$ & $2.74(1.31-25.10)$ & 0.032 \\
\hline
\end{tabular}




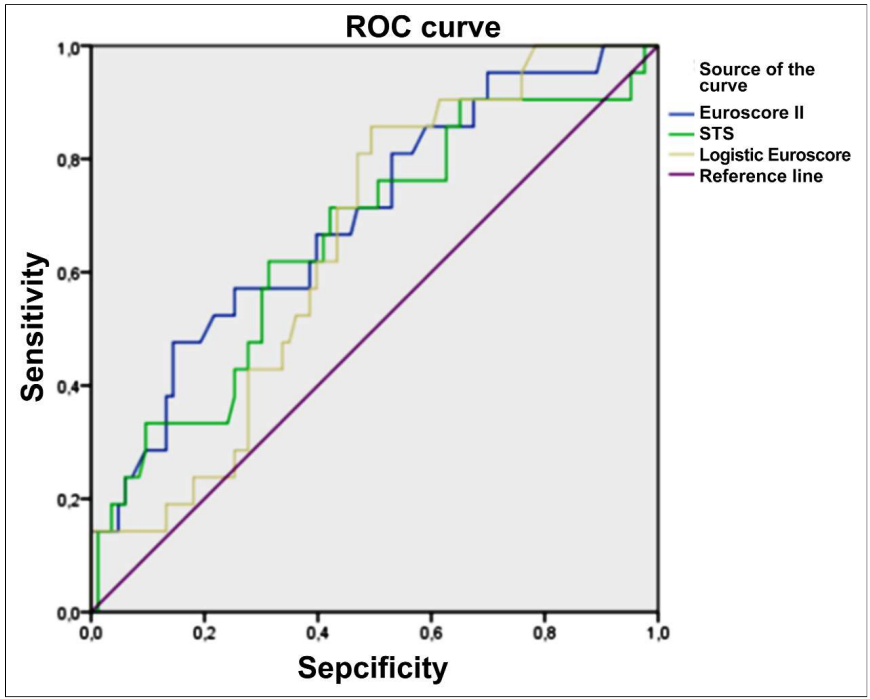

Figure 1: Receiver-operating characteristic curves indicating the discriminative ability of the risk scoring systems.

disease, carotid artery disease, and current smoking. In addition, cardiopulmonary bypass time and left atrial diameter were higher in patients developing POAF.

Even though Syntax score was not different between groups, Syntax II score was higher in POAF-positive patients compared to the POAF-negative patients. Moreover, all risk scoring systems, Euroscore II, STS and Logistic Euroscore were statistically different between POAF-positive and POAF-negative groups. This comparison of risk systems was depicted in Table II.

ROC curve analysis was used to determine discriminative ability of each risk score system (Figure 1). Euroscore II had better area under the ROC curve than other systems (0.697). This was followed by STS $(0.658)$ and logistic Euroscore (0.652). Euroscore II could be preferred for the larger area under the ROC curve.

Cut-off points for the prediction of POAF were used to indicate sensitivity and specificity. Cut-off point for Euroscore II was 2.56, with a sensitivity of $47 \%$ and a specificity of $85 \%(p=0.002)$. It was 1.136 for STS, with a sensitivity of $61 \%$ and a specificity of $69 \%(p=0.021)$. Finally, for logistic Euroscore cut-off was 2.1, with a sensitivity of $85 \%$ and a specificity of $51 \%(p=0.010)$.

Logistic regression was applied and significant independent variables were put into the multiple logistic regression. PAD and cardiopulmonary bypass time was found to be related with the development of POAF independently, with $\beta=-2.818$ and $0.028, p=0.022$ and $0.045, \mathrm{OR}=0.060$ and 1.028 , and $95 \% \mathrm{Cl}$ of $0.005-0.662$ and $1.00-1.050$, respectively.

\section{DISCUSSION}

This study indicates that Euroscore II can be more preferable compared with Logistic Euroscore and STS score for the prediction of postoperative atrial fibrillation.
Nevertheless, all the risk models were originally developed for the prediction of mortality, all of them were also associated with POAF according to this study.

Atrial fibrillation after CABG is related with increased mortality, stroke and duration of hospital stay. 7,8 In this study, peripheral artery and carotid artery disease, current smoking, left atrium diameter, cardiopulmonary bypass time were found to be associated with POAF. There is growing proof about an increased risk of AF in patients with peripheral artery disease. 9 This study contributes to the current evidence by showing that PAD is also related with POAF. Moreover, carotid atherosclerosis is proposed to a risk factor for developing AF. 10 As a routine preoperative examination, all the patients were investigated with carotid ultrasonography. Patients with carotid artery disease were likewise at risk of POAF with respect to this study. The effect of smoking on AF is a debated topic in recent studies. ${ }^{11}$ Even though, the Rotterdam study indicated elevated risk of AF among current and former smokers, the Danish Diet, Cancer, and Health Study showed no effect of smoking on AF.12,13 Current smoking was significantly higher in patients with POAF.

POAF is an expected arrhythmia as a result of cardiopulmonary bypass and reperfusion after ischemic cardioplegia. 14 In this study, rise in cardiopulmonary bypass time led to increase in POAF development, which supported the previous findings.

Syntax and Syntax II scores were also evaluated in this study. Syntax score indicates the complexity of coronary artery disease and is linked with adverse events after surgical or percutaneous revascularization. ${ }^{15,16} \mathrm{Gecmen}$ et al. concluded that Syntax score was higher in POAFdeveloped patients. ${ }^{3}$ However, in this study, it was not found to be related with POAF in contradiction to the mentioned study. Adding clinical factors to Syntax score led to change in this matter. Syntax II (also known as clinical Syntax score) was associated with POAF in our trial. This finding was compatible with previous study conducted by Oktay et al. ${ }^{8}$

Numerous cardiac risk systems to assess surgical mortality have been introduced. Performance analysis of Euroscore II, logistic Euroscore and STS were compared in various studies to evaluate CABG, valve surgeries, transcatheter aortic valve implantation (TAVI) and percutaneous mitral valve repair. 17 Besides from mortality analysis, prediction of some postoperative complications, such as acute kidney injury, was applied by current risk scoring systems. ${ }^{18}$ Comparison of surgical risk score systems to predict POAF was aimed as a new approach in our study. To the best of authors' knowledge, this is the first study to compare cardiac risk scores for the prediction of POAF following isolated CABG. According to our study, all risk models can be used to predict POAF. Yet, the discriminatory ability of 
Euroscore II was slightly found to be higher than that of the STS score and Logistic Euroscore for POAF following isolated CABG.

A number of studies comparing these three risk scores for the prediction of operative mortality have been published. Ad el al. demonstrated that discriminatory ability of Euroscore II for surgical mortality was slightly better than STS. This finding was compatible with our evidence indicating the same prediction ability for POAF.19 On the contrary, Kunt et al. showed that Euroscore II underestimated the mortality and was inferior to logistic Euroscore and STS in this manner. 12 It was indicated that Logistic Euroscore overpredicted the mortality in some studies. According to ROC analysis, AUC for logistic Euroscore was lower than Euroscore II and STS in our study. This finding indicated that the predictive ability of logistic Euroscore was barely lower than the other ones for POAF.

Limitations of the study were as follows: Firstly, the study population included a relatively small number of patients. Furthermore, it was restricted to the patients underwent isolated CABG, not valvular surgery. Population size is not sufficient to draw certain assessments. Because of multifactorial nature of POAF, scoring systems might lead to inaccurate prediction of POAF

\section{CONCLUSION}

Euroscore II, STS and Logistic Euroscore were all associated with postoperative atrial fibrillation. Among them, Euroscore II seems to be more preferable to predict AF development.

\section{ETHICAL APPROVAL:}

Ethical approval was obtained from Istanbul Yeni Yuzyil University prior to initiation of the research work.

\section{PATIENTS' CONSENT:}

Informed consent was obtained from patients to publish the data.

\section{CONFLICT OF INTEREST:}

Authors declared no conflict of interest.

\section{AUTHORS' CONTRIBUTION:}

$A D, F G, K S$, SK: Made contributions to the conception, design, data collection of the study, review of the literature, analysis of the results, writing of the manuscript.

MY, EO: Data collection, statistical analysis

DM, NK: Review of the manuscipt, supervision of the study, writing and final approval.

\section{REFERENCES}

1. Kirchhof P, Benussi S, Kotecha D, Ahlsson A, Atar D, Casadei B, et al. 2016 ESC guidelines for the management of atrial fibrillation developed in collaboration with EACTS. Eur Heart $J$ 2016; 37:2893-962.
2. Ad N, Barnett SD, Haan CK, O'Brien SM, Milford-Beland S, Speir AM. Does preoperative atrial fibrillation increase the risk for mortality and morbidity after coronary artery bypass grafting? J Thorac Cardiovasc Surg 2009; 137:901-6.

3. Geçmen Ç, Babür Güler G, Erdogan E, Hatipoglu S, Güler E, Yilmaz F, et al. Syntax score predicts postoperative atrial fibrillation in patients undergoing on-pump isolated coronary artery bypass grafting surgery. Anatol J Cardiol 2016; 16:655-61.

4. Nashef SA, Roques F, Sharples LD, Nilsson J, Smith C, Goldstone AR, et al. Euroscore II. Eur J Cardiothorac Surg 2012; 41:734-45.

5. Kortlandt FA, van 't Klooster CC, Bakker AL, Swaans MJ, Kelder JC, de Kroon TL, et al. The predictive value of conventional surgical risk scores for periprocedural mortality in percutaneous mitral valve repair. Neth Heart J 2016; 24:475-80.

6. Ahlsson A, Fengsrud E, Bodin L, Englund A. Postoperative atrial fibrillation in patients undergoing aortocoronary bypass surgery carries an eightfold risk of future atrial fibrillation and a doubled cardiovascular mortality. Eur J Cardiothorac Surg 2010; 37:353-9.

7. Mariscalco G, Engström KG. Postoperative atrial fibrillation is associated with late mortality after coronary surgery, but not after valvular surgery. Ann Thorac Surg 2009; 88:1871-6.

8. Oktay V, Cirali IÇ, Sinan UY, Yildiz A, Ersanli MK, Ozsoy D, et al. Validation of syntax and clinical syntax scores in predicting atrial fibrillation following on-pump coronary artery bypass grafting. Turk Gogus Kalp Dama 2017; 25:333-9.

9. O'Neal WT, Efird JT, Nazarian S, Alonso A, Heckbert SR, Soliman EZ. Peripheral arterial disease and risk of atrial fibrillation and stroke: The multi-ethnic study of atherosclerosis. J Am Heart Assoc 2014; 3:e001270.

10. Willeit K, Pechlaner R, Egger G, Weger S, Oberhollenzer M, Willeit $\mathrm{J}$, et al. Carotid atherosclerosis and incident atrial fibrillation. Arterioscler Thromb Vasc Biol 2013; 33:2660-5.

11. Seccia TM, Calò LA. Smoking causes atrial fibrillation? Further evidence on a debated issue. Eur J Prev Cardiol 2018; 25: 1434-6.

12. Heeringa J, Kors JA, Hofman A, van Rooij FJ, Witteman JC. Cigarette smoking and risk of atrial fibrillation: The Rotterdam study. Am Heart J 2008; 156:1163-9.

13. Frost L, Hune LJ, Vestergaard P. Overweight and obesity as risk factors for atrial fibrillation or flutter: The Danish diet, Cancer, and Health Study. Am J Med 2005; 118:489-95.

14. Zakkar M, Ascione R, James AF, Angelini GD, Suleiman MS. Inflammation, oxidative stress and postoperative atrial fibrillation in cardiac surgery. J Stroke Cerebrovasc 2016; 25:1396-402.

15. Lemesle G, Bonello L, de Labriolle A, Steinberg DH, Roy P, Pinto Slottow TL, et al. Prognostic value of the SYNTAX score in patients undergoing coronary artery bypass grafting for threevessel coronary artery disease. Catheter Cardiovasc Interv 2009; 73:612-7.

16. Valgimigli M, Serruys PW, Tsuchida K Vaina S, Morel MA, Van den Brand $\mathrm{MJ}$, et al. Cyphering the complexity of coronary artery disease using the syntax score to predict clinical outcome in patients with three-vessel lumen obstruction undergoing percutaneous coronary intervention. Am J Cardiol 2007; 99:1072-81 
17. Wendt D, Thielmann M, Kahlert $P$, Kastner S, Price V, Al-Rashid $\mathrm{F}$, et al. Comparison between different risk scoring algorithms on isolated conventional or transcatheter aortic valve replacement. Ann Thorac Surg 2014; 97:796-802.

18. Chen SW, Chang CH, Fan PC, Chen YC, Chu PH, Chen TH, et al. Comparison of contemporary preoperative risk models at predicting acute kidney injury after isolated coronary artery bypass grafting: A retrospective cohort study. BMJ Open 2016; 6:e010176

19. Ad N, Holmes SD, Patel J, Pritchard G, Shuman DJ, Halpin L. Comparison of euroscore II, Original euroscore and the society of thoracic surgeons risk score in cardiac surgery patients. Ann Thorac Surg 2016; 102:573-9.

20. Kunt AG, Kurtcephe M, Hidiroglu M, Cetin L, Kucuker A, Bakuy V. Comparison of original euroscore, euroscore II and STS risk models in a Turkish cardiac surgical cohort. Interact Cardiovasc Thorac Surg 2013; 16:625-9.

21. Durand E, Borz B, Godin M, Tron C, Litzler PY, Bessou JP, et al. Performance analysis of euroscore II compared to the original logistic euroscore and STS scores for predicting 30day mortality after transcatheter aortic valve replacement. Am J Cardiol 2013; 111:891-7.

.......... 